\title{
Identification of a Novel Series of Potent TrkA Receptor Tyrosine Kinase Inhibitors
}

\author{
Stéphane L. Raeppel, ${ }^{1}$ Frédéric Gaudette, ${ }^{1}$ Hannah Nguyen, ${ }^{2}$ Normand Beaulieu, ${ }^{3}$ \\ James Wang, ${ }^{4}$ Christiane Maroun, ${ }^{3}$ Jeffrey M. Besterman, ${ }^{3}$ and Arkadii Vaisburg ${ }^{1}$ \\ ${ }^{1}$ Department of Medicinal Chemistry, MethylGene Inc., 7150 Rue Frederick-Banting, Suite 200, Montréal, QC, Canada H4S $2 A 1$ \\ ${ }^{2}$ Department of Cell Biology and Pharmacology, MethylGene Inc., 7150 Rue Frederick-Banting, Suite 200, \\ Montréal, QC, Canada H4S 2A1 \\ ${ }^{3}$ Department of Cell Biology and Pharmacology, MethylGene Inc., 7150 Rue Frederick-Banting, Suite 200, Montréal, \\ QC, Canada H4S $2 A 1$ \\ ${ }^{4}$ Department of PK/Analytical Chemistry, MethylGene Inc., 7150 Rue Frederick-Banting, Suite 200, Montréal, QC, Canada H4S $2 A 1$
}

Correspondence should be addressed to Stéphane L. Raeppel, raeppels@chemrf.com

Received 5 December 2011; Revised 13 February 2012; Accepted 13 February 2012

Academic Editor: O. Bruno

Copyright (C) 2012 Stéphane L. Raeppel et al. This is an open access article distributed under the Creative Commons Attribution License, which permits unrestricted use, distribution, and reproduction in any medium, provided the original work is properly cited.

A novel series of $\mathrm{N}$-(3-(6-substituted-aminopyridin-3-yloxy)phenyl)-2-oxo-3-phenylimidazolidine-1-carboxamides targeting TrkA receptor tyrosine kinase was identified. SAR study of the series allowed us to design and synthesize compounds possessing inhibitory activity of TrkA kinase enzyme in the low nanomolar range with low residual activity against c-Met and with no significant activity against VEGFR2.

Tropomyosin-related kinases (Trks) are receptor tyrosine kinases normally expressed in neuronal tissue where they play important role in both development and function of the nervous system [1]. The Trk receptor family is composed of three members (A, B, and C) activated by specific ligands called neurotrophins (NT). Each Trk receptor contains an extracellular domain (ligand binding), a transmembrane region, and an intracellular domain (including kinase domain) which upon binding of their respective ligand (nerve growth factor (NGF) for TrkA, brain-derived growth factor (BDNF) and NT-4/5 for TrkB, and NT3 for TrkC) triggers oligomerization of the receptors, phosphorylation of specific tyrosine residues in the kinase domain, and downstream signal transduction pathways, including survival, proliferation, and differentiation in normal and neoplastic neuronal cells [2-4]. While Trks are expressed at low levels outside the nervous system in the adult, deregulation of TrkA and TrkB and their cognate ligands has been described in numerous types of cancers including prostate, breast, colorectal, ovarian, lung, pancreas, melanoma, thyroid, and neuroblastoma and occurs mainly through wild type receptor overexpression, activation, amplification, and/or mutation $[5,6]$. Importantly, increased Trks activation in tumor tissues correlates with an aggressive phenotype and poor clinical outcome [6].

There are a limited number of reported selective TrkA receptor tyrosine kinase inhibitors in the literature (Figure 1) [7-9]. Developed by Cephalon (now a group member of Teva Pharmaceutical Industries Ltd.), lestaurtinib (CEP701) is a potent multitargeted tyrosine kinases inhibitor targeting mainly TrkA, Flt3, and JAK2 and is in clinical trials for the treatment of myeloproliferative disorders $[10,11]$. More recently, Cephalon disclosed indenopyrrolocarbazole 12a as a potent and selective TrkA inhibitor displaying antitumor properties [12]. Moreover, organorutheniumpyridocarbazole $\left(\mathbf{R}_{\mathbf{R u}}\right)-21$ from Pagano et al. [13], oxindole 3 from GSK [14], isothiazole $\mathbf{5 n}$ from Pfizer [15], thiazole $\mathbf{2 0 h}$ from BMS [16], and AZ-23 from AstraZeneca were reported as potent and selective TrkA inhibitors as well $[17,18]$.

We have previously reported on four novel series of kinase inhibitors with a 2-oxo-3-phenylimidazolidine-1carboxamide head group based on thieno[3,2-b]pyridine 

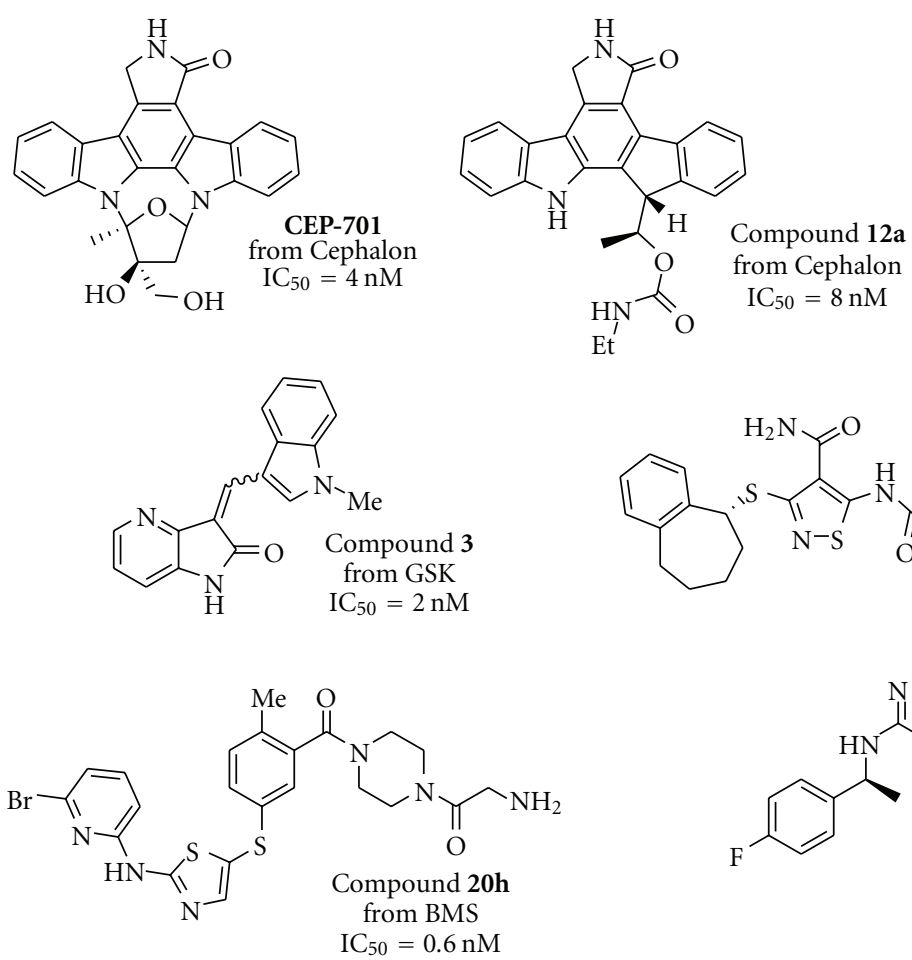

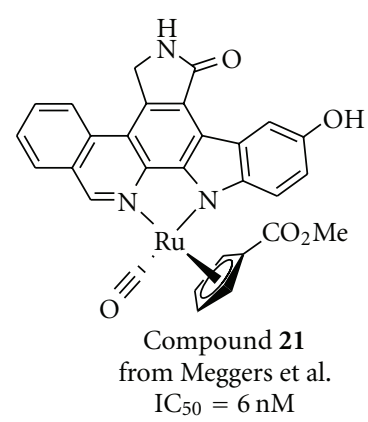

Compound $5 n$

from Pfizer

$\mathrm{IC}_{50}<1 \mathrm{nM}$

Figure 1: TrkA inhibitors disclosed in the literature and their reported $\mathrm{IC}_{50}$ and/or $\mathrm{EC}_{50}$.<smiles>[X]N=[W]N=[Y]</smiles><smiles>[R]c1cc(NC(=O)N2CCN(c3ccccc3)C2=O)cc(Oc2ccc([R])nc2)c1</smiles>

FIGURE 2: Transposition from 1,4- into 1,3-substitution pattern for the central phenyl ring.

[19], quinoline [20], pyrimidine, and pyridine scaffolds [21], exemplified by structures $1-4$, respectively (Table 1 ). Bi-cyclic RTK inhibitors 1 and 2 strongly inhibited both c-Met and VEGFR2 enzymes while compounds $\mathbf{3}$ and $\mathbf{4}$ showed some preference for the c-Met kinase enzyme. In our efforts to identify new kinase inhibitors with a different kinase inhibitory profile from the ones of compounds 1-4 (and their analogues), we viewed compound 4 as a valuable starting point for further exploration. As the first exercise, we changed the substitution pattern between the central phenyl ring and the pyridine core of compound 4 as illustrated in Figure 2 (transposition from 1,4- to 1,3-substitution pattern like in isothiazole $5 \mathrm{n}$ from Pfizer, thiazole $20 \mathrm{~h}$ from BMS, and pyrimidine AZ-23 from AstraZeneca), thus synthesizing compound $\mathbf{5}$. This compound was roughly ten times weaker than the parent compound 4 against both c-Met and VEGFR2 enzymes, but surprisingly showed potent inhibition of TrkA when tested at $0.1 \mu \mathrm{M}$. As a consequence, we initiated the SAR study around compound $\mathbf{5}$ as a prototype of selective TrkA inhibitors. The $\mathrm{IC}_{50}$ of compound $\mathbf{5}$ was determined to be $4 \mathrm{nM}$ against the TrkA human enzyme.
A straightforward synthesis of the target molecule $\mathbf{5}$ was developed and is illustrated in Scheme 1. (The details for the synthesis and the characterization of all the new compounds are well described in [21].) 5-Bromo-2-nitropyridine was reacted with 3-aminophenol in the presence of cesium carbonate in acetonitrile at room temperature. The choice of the base, solvent, and temperature is critical in order to obtain the intermediate $\mathbf{A}$ in fairly good yield; otherwise multiple products are formed. Intermediate $\mathbf{A}$ was subsequently reacted with 2-oxo-3-phenylimidazolidine-1carbonyl chloride generated in situ from the reaction between 1-phenylimidazolidin-2-one and triphosgene to afford intermediate $\mathbf{B}$. After reduction of the nitro group and subsequent derivatization of 6-aminopyridine intermediate $\mathrm{C}$, compound $\mathbf{5}$ was obtained in good yield.

To continue with the SAR study around compound 5, we explored the replacement of the oxygen linker by keeping unchanged the 2-oxo-3-phenylimidazolidine-1-carboxamide head group, which is presumed to occupy the hydrophobic back pocket of the kinase catalytic domain, and 6-acetamidopyridine scaffold, which is supposed to 
TABLE 1: 2-Oxo-3-phenylimidazolidine-1-carboxamide kinase inhibitors based on different scaffolds.

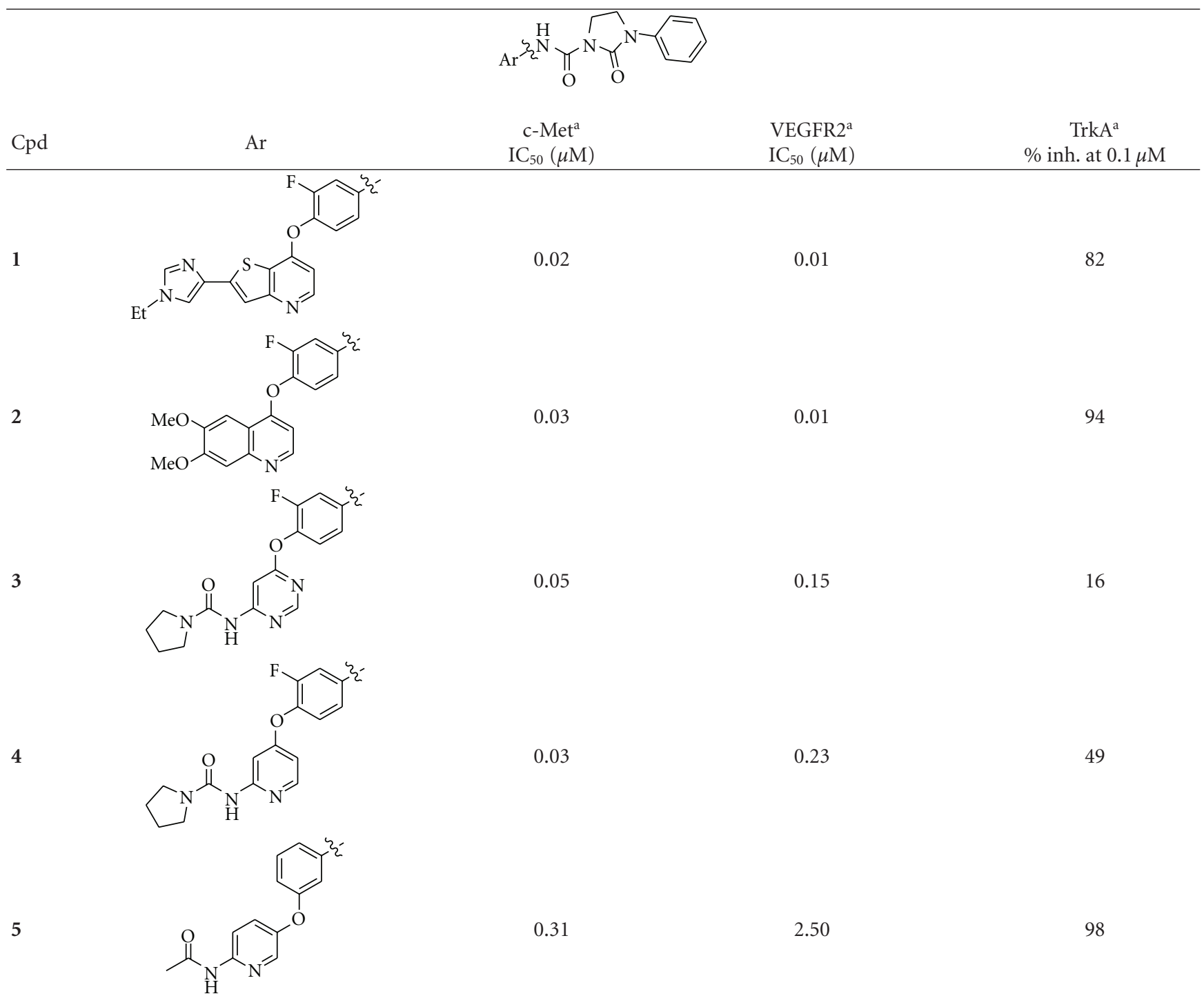

${ }^{a} \mathrm{IC}_{50}$ and percentage of inhibition values are reported as the average of $\geq 3$ experiments.

interact with the ATP catalytic site in the hinge region of the target kinase enzyme (Table 2). Not surprisingly, the replacement of the oxygen linker in compound 5 by an ureido, ethynyl, sulfamoyl, or carbamoyl spacer (compounds 6-9) completely abolished the activity against TrkA kinase enzyme.

We next investigated the presence of a small substituent located on the central phenyl ring (positions 2 and 4) of compound 5 (Table 3 ). In contrast with either thiazole $\mathbf{2 0 h}$ from Bristol-Myers Squib [16] or AZ-23 from AstraZeneca $[17,18]$ (Figure 1), in which the presence of a small substituent on the central phenyl or pyridinyl ring improves the activity and the selectivity against the TrkA kinase enzyme, in our series of compounds that trend was not observed. Thus, compounds 10-12 turned out to be inactive against TrkA.

We finally examined the influence of each extremity of compound $\mathbf{5}$ where $\mathrm{R}^{1}$ is presumed to extend into the solvent exposed area and $\mathrm{R}^{2}$ is thought to occupy the hydrophobic back pocket of the kinase catalytic domain-both sites potentially capable of modulating physicochemical and pharmacokinetic properties of the inhibitors (compounds 1317, Table 4). Removal of the acetyl group from compound 5 afforded compound $\mathbf{1 3}$ with a lower potency against TrkA, probably due to the absence of a strong hydrogen bond donor (NH amide) and/or a hydrogen bond acceptor (carbonyl amide) which is presumed to interact with the hinge region of the kinase binding domain. Introduction of relatively small electronegative fluorine in the para position of the phenyl ring is well tolerated (compound 14). Finally, replacement of the acetamido group by a functionalized ureido moiety is also accepted, giving rise to potent TrkA inhibitors (compounds 15-17) and allowing us to incorporate water solubilizing groups.

Compound $\mathbf{5}$ was profiled and tested at $100 \mathrm{nM}$ against 24 other kinase enzymes using Millipore's Kinaseprofiler 
<smiles>Nc1cccc(Oc2ccc([N+](=O)[O-])nc2)c1</smiles><smiles>O=C(Cl)N1CCN(c2ccccc2)C1=O</smiles><smiles>CC(=O)Nc1ccc(Oc2cccc(NC(=O)N3CCN(c4ccccc4)C3=O)c2)cn1</smiles>

Scheme 1: Synthesis of compound 5: (a) $\mathrm{Cs}_{2} \mathrm{CO}_{3}, \mathrm{MeCN}$, rt; (b) DIPEA, DCM, rt; (c) iron, $\mathrm{NH}_{4} \mathrm{Cl}, \mathrm{MeOH} /$ water, reflux; (d) Ac $\mathrm{O}$, rt.

TABLE 2: Influence of the linker in the 6-acetamidopyridine series on the TrkA potency.<smiles>CC(=O)Nc1ccc([IH]c2cccc(NC(=O)N3CC4CCC3C4c3ccccc3)c2)cn1</smiles>

\begin{tabular}{|c|c|c|}
\hline Cpd & $\mathrm{L}$ & $\begin{array}{c}\text { TrkA }^{\text {a }} \\
\% \text { inh. at } 30 \mathrm{nM}\end{array}$ \\
\hline 5 & $\mathrm{O}$ & 96 \\
\hline 6 & C & 5 \\
\hline 7 & & 16 \\
\hline 8 & & 6 \\
\hline 9 & C & 2 \\
\hline
\end{tabular}

a percentage of inhibition values are reported as the average of $\geq 3$ experiments.

assay services. In addition to targeting TrkA receptor tyrosine kinase (98\% inhibition), it was also moderately active against Flt3 (83\% inhibition) but, importantly, did not show significant inhibitory activity against the other representative human kinases (<40\% inhibition): ALK, Bmx, CHK1, cKit, c-Raf, EphB4, FAK, GSK3 $\beta$, Haspin, IKK $\beta$, JAK2, JAK3, LIMK1, MEK1, c-Met, PDK1, PI3-Kinase $\beta, \operatorname{Pim}-1, \operatorname{PKB} \alpha$,
TABLE 3: Influence of the central phenyl ring substistution in the 6-acetamidopyridine series on the TrkA potency.<smiles>[R1]c1cc(NC(=O)N2CCN(c3ccccc3)C(=O)C2)ccc1Oc1ccc(NC(C)=O)nc1</smiles>

\begin{tabular}{|c|c|c|c|}
\hline Cpd & $\mathbf{R}^{1}$ & $\mathbf{R}^{2}$ & $\begin{array}{c}\operatorname{TrkA}^{\mathrm{a}} \\
\% \text { inh. at } 30 \mathrm{nM}\end{array}$ \\
\hline 5 & $\mathrm{H}$ & $\mathrm{H}$ & 96 \\
\hline 10 & $\mathrm{Me}$ & $\mathrm{H}$ & 6 \\
\hline 11 & $\mathrm{OMe}$ & $\mathrm{H}$ & 15 \\
\hline 12 & $\mathrm{H}$ & $\mathrm{Cl}$ & 0 \\
\hline
\end{tabular}

Ret, Ron, and Tie2. When tested at $10 \mathrm{nM}$ against TrkB, compound 5 showed $40 \%$ inhibition.

Compound 5 was further evaluated for its pharmacokinetic properties in the rat (Table 5). Compound 5 showed a $1.5 \mathrm{~h}$ half-life, a high rate of clearance, an appreciable steadystate volume of distribution, and excellent oral bioavailability.

In conclusion, a novel series of $N$-(3-(6-substituted-aminopyridin-3-yloxy)phenyl)-2-oxo-3-phenylimidazolidine-1carboxamides was designed and synthesized. The most attractive compounds of the series - 5 and 14-17-are selective for the TrkA kinase enzyme in the low nanomolar 
TABLE 4: Influence of $\mathbf{R}^{1}$ and $\mathbf{R}^{2}$ substituents on the TrkA potency.

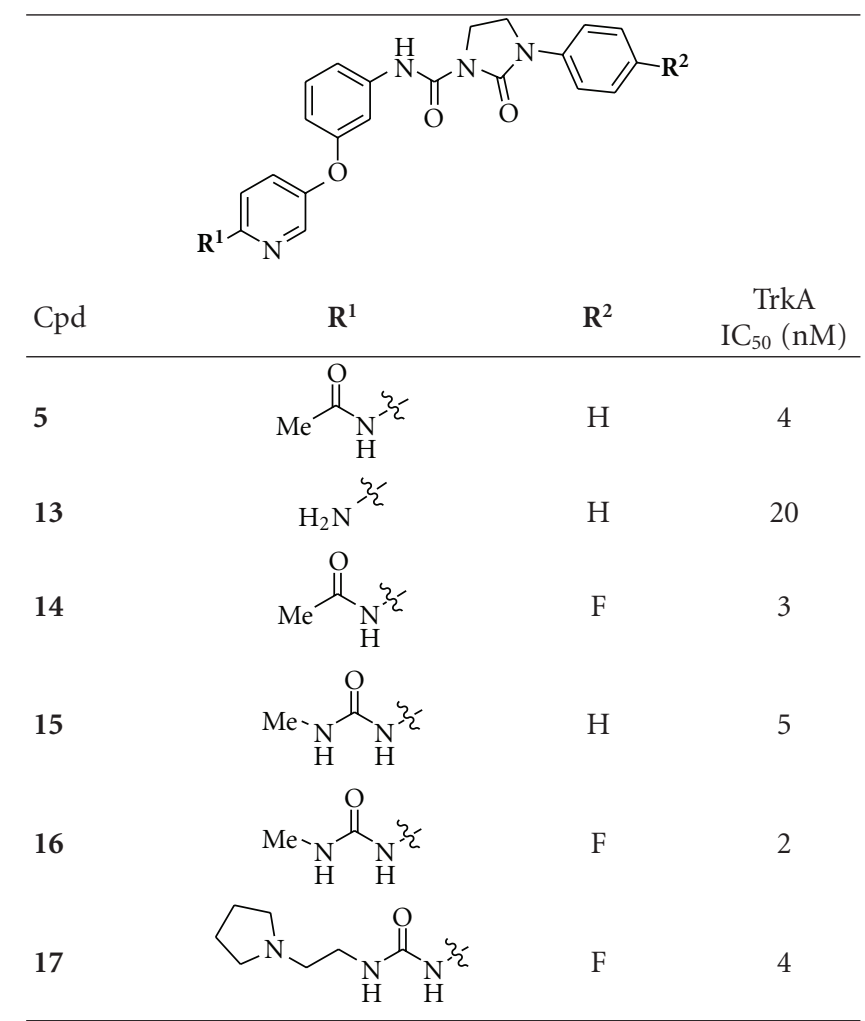

${ }^{\mathrm{a}} \mathrm{IC}_{50}$ values are reported as the average of $\geq 2$ experiments.

TABLE 5: Rat pharmacokinetic profile of compound 5.

\begin{tabular}{lc}
\hline PK properties $^{\mathrm{a}}$ & Cpd $\mathbf{5}$ \\
\hline $\mathrm{T}_{1 / 2}(\mathrm{~h})$, i.v. & 1.5 \\
$\mathrm{Cl}(\mathrm{L} / \mathrm{h} / \mathrm{kg})$ i.v. & 3.3 \\
$V$ ss $(\mathrm{L} / \mathrm{kg})$ i.v. & 3.7 \\
$t_{\max }(\mathrm{h})$, p.o. & 4.0 \\
$N . C_{\max }[\mu \mathrm{M} /(\mathrm{mg} / \mathrm{kg})]$, p.o. & 0.08 \\
N. AUC $[\mu \mathrm{M} . \mathrm{h} /(\mathrm{mg} / \mathrm{kg})]$, p.o. & 0.83 \\
$F(\%)$ & 99
\end{tabular}

i.v. dose: $2.58 \mathrm{mg} / \mathrm{kg}$; p.o. dose: $5.25 \mathrm{mg} / \mathrm{kg}$.

range (comparable with the known TrkA inhibitors) with only residual activity against other RTKs. These novel chemical entities represent a valuable starting point in design and synthesis of TrkA selective inhibitors both as tools to further validate TrkA as a promising biological target and for the development of potential new anticancer therapies.

\section{Acknowledgment}

The authors thank Dr. Ljubomir Isakovic for the synthesis of compound 4.

\section{References}

[1] A. Patapoutian and L. F. Reichardt, "Trk receptors: mediators of neurotrophin action," Current Opinion in Neurobiology, vol. 11, no. 3, pp. 272-280, 2001.

[2] E. J. Huang and L. F. Reichardt, "Trk receptors: roles in neuronal signal transduction," Annual Review of Biochemistry, vol. 72, pp. 609-642, 2003.

[3] L. F. Reichardt, "Neurotrophin-regulated signalling pathways," Philosophical Transactions of the Royal Society B, vol. 361, no. 1473, pp. 1545-1564, 2006.

[4] S. D. Skaper, "The biology of neurotrophins, signalling pathways, and functional peptide mimetics of neurotrophins and their receptors," CNS and Neurological Disorders - Drug Targets, vol. 7, no. 1, pp. 46-62, 2008.

[5] G. M. Brodeur, J. E. Minturn, R. Ho et al., "Trk receptor expression and inhibition in neuroblastomas," Clinical Cancer Research, vol. 15, no. 10, pp. 3244-3250, 2009.

[6] C. J. Thiele, Z. Li, and A. E. McKee, "On Trk-the TrkB signal transduction pathway is an increasingly important target in cancer biology," Clinical Cancer Research, vol. 15, no. 19, pp. 5962-5967, 2009.

[7] R. L. Hudkins and K. A. Josef, "Pyrazole trk kinase inhibitors for the treatment of cancer," Expert Opinion on Therapeutic Patents, vol. 17, no. 3, pp. 351-356, 2007.

[8] T. Wang, D. Yu, and M. L. Lamb, "Trk kinase inhibitors as new treatments for cancer and pain," Expert Opinion on Therapeutic Patents, vol. 19, no. 3, pp. 305-319, 2009.

[9] K. J. Martin, N. Shpiro, R. Traynor, M. Elliott, and J. S. C. Arthur, "Comparison of the specificity of Trk inhibitors in recombinant and neuronal assays," Neuropharmacology, vol. 61, no. 1-2, pp. 148-155, 2011.

[10] S. J. Miknyoczki, H. Chang, A. Klein-Szanto, C. A. Dionne, and B. A. Ruggeri, "The Trk tyrosine kinase inhibitor CEP-701 (KT-5555) exhibits significant antitumor efficacy in preclinical xenograft models of human pancreatic ductal adenocarcinoma," Clinical Cancer Research, vol. 5, no. 8, pp. 2205-2212, 1999.

[11] D. E. Gingrich, S. X. Yang, G. W. Gessner, T. S. Angeles, and R. L. Hudkins, "Synthesis, modeling, and in vitro activity of (3'S)-epi-K-252a analogues. Elucidating the stereochemical requirements of the 3 '-sugar alcohol on trkA tyrosine kinase activity," Journal of Medicinal Chemistry, vol. 48, no. 11, pp. 3776-3783, 2005.

[12] R. Tripathy, T. S. Angeles, S. X. Yang, and J. P. Mallamo, “TrkA kinase inhibitors from a library of modified and isosteric Staurosporine aglycone," Bioorganic and Medicinal Chemistry Letters, vol. 18, no. 12, pp. 3551-3555, 2008.

[13] N. Pagano, E. Y. Wong, T. Breiding et al., "From imide to lactam metallo-pyridocarbazoles: distinct scaffolds for the design of selective protein kinase inhibitors," Journal of Organic Chemistry, vol. 74, no. 23, pp. 8997-9009, 2009.

[14] E. R. Wood, L. Kuyper, K. G. Petrov, R. N. Hunter, P. A. Harris, and K. Lackey, "Discovery and in vitro evaluation of potent TrkA kinase inhibitors: oxindole and aza-oxindoles," Bioorganic and Medicinal Chemistry Letters, vol. 14, no. 4, pp. 953957, 2004.

[15] B. Lippa, J. Morris, M. Corbett et al., "Discovery of novel isothiazole inhibitors of the TrkA kinase: structure-activity relationship, computer modeling, optimization, and identification of highly potent antagonists," Bioorganic and Medicinal Chemistry Letters, vol. 16, no. 13, pp. 3444-3448, 2006.

[16] S. H. Kim, J. S. Tokarski, K. J. Leavitt et al., "Identification of 2-amino-5-(thioaryl)thiazoles as inhibitors of nerve growth 
factor receptor TrkA," Bioorganic and Medicinal Chemistry Letters, vol. 18, no. 2, pp. 634-639, 2008.

[17] T. Wang, M. L. Lamb, D. A. Scott et al., "Identification of 4aminopyrazolylpyrimidines as potent inhibitors of Trk kinases," Journal of Medicinal Chemistry, vol. 51, no. 15, pp. 4672-4684, 2008.

[18] K. Thress, T. MacIntyre, H. Wang et al., "Identification and preclinical characterization of AZ-23, a novel, selective, and orally bioavailable inhibitor of the Trk kinase pathway," Molecular Cancer Therapeutics, vol. 8, no. 7, pp. 1818-1827, 2009.

[19] S. Raeppel, S. Claridge, O. Saavedra et al., "N-(3-fluoro-4-(2arylthieno[3,2-b]pyridin-7-yloxy)phenyl)-2-oxo-3phenylimidazolidine-1-carboxamides: a novel series of dual c-Met/VEGFR2 receptor tyrosine kinase inhibitors," Bioorganic and Medicinal Chemistry Letters, vol. 19, no. 5, pp. 1323-1328, 2009.

[20] M. Mannion, S. Raeppel, S. Claridge et al., "N-(4-(6,7-Disubstituted-quinolin-4-yloxy)-3-fluorophenyl)-2-oxo-3-phenylimidazolidine-1-carboxamides: A novel series of dual c-Met/ VEGFR2 receptor tyrosine kinase inhibitors," Bio-organic and Medicinal Chemistry Letters, vol. 19, no. 23, pp. 6552-6556, 2009.

[21] S. Raeppel, O. Saavedra, S. Claridge et al., "Kinase inhibitors and uses thereof," Patent application WO 2008/046216. 


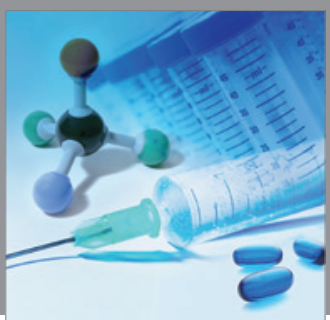

International Journal of

Medicinal Chemistry

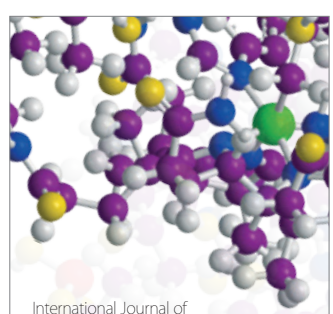

Carbohydrate Chemistry

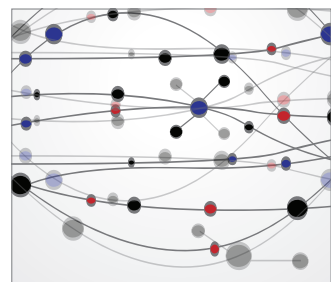

The Scientific World Journal
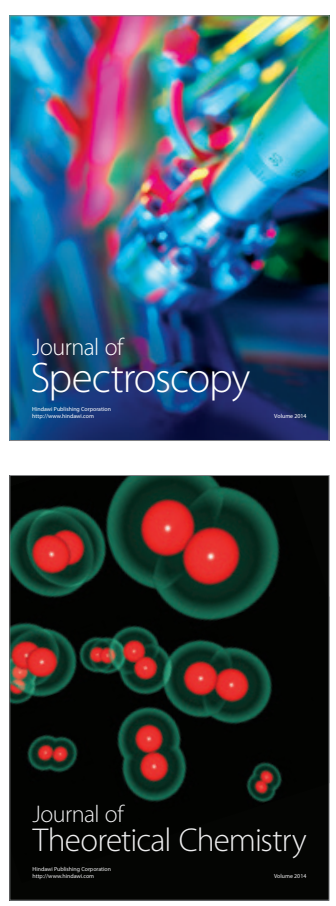
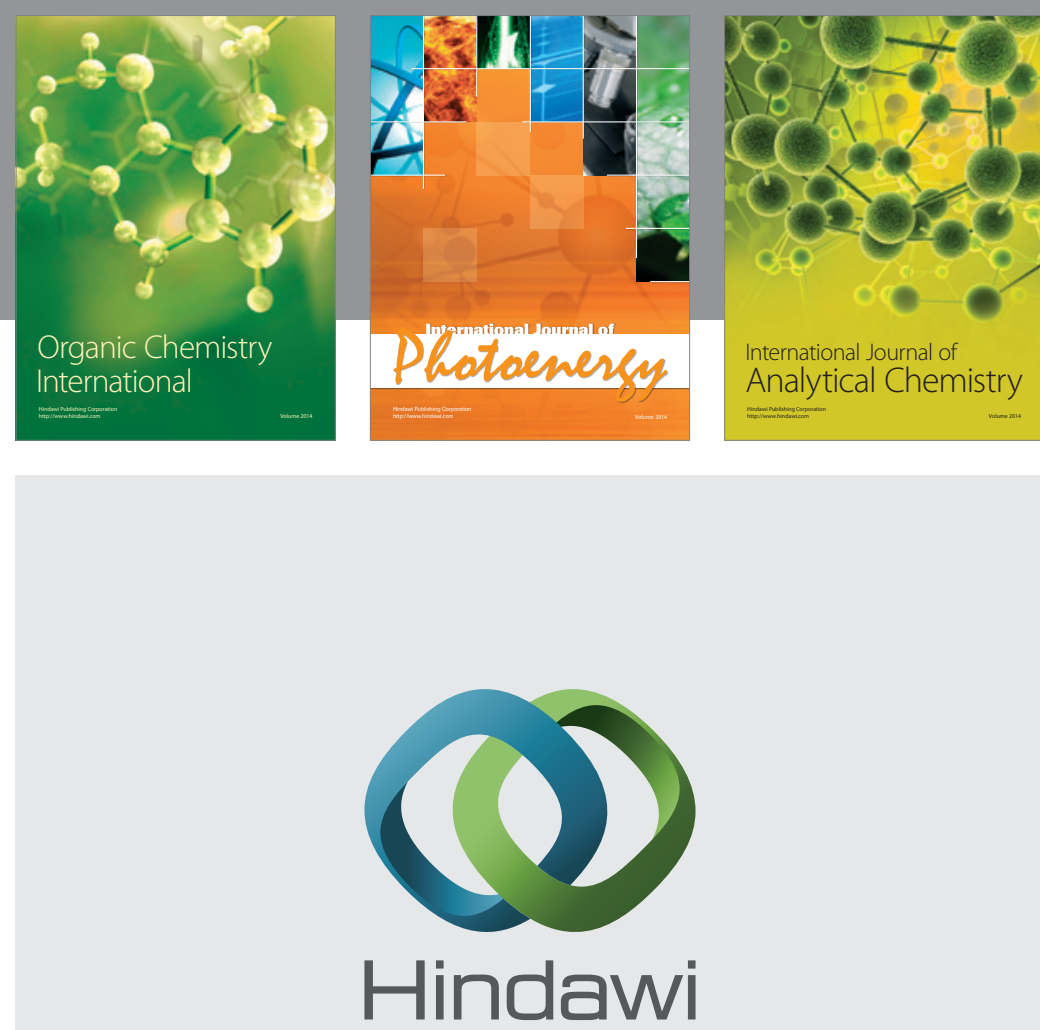

Submit your manuscripts at

http://www.hindawi.com
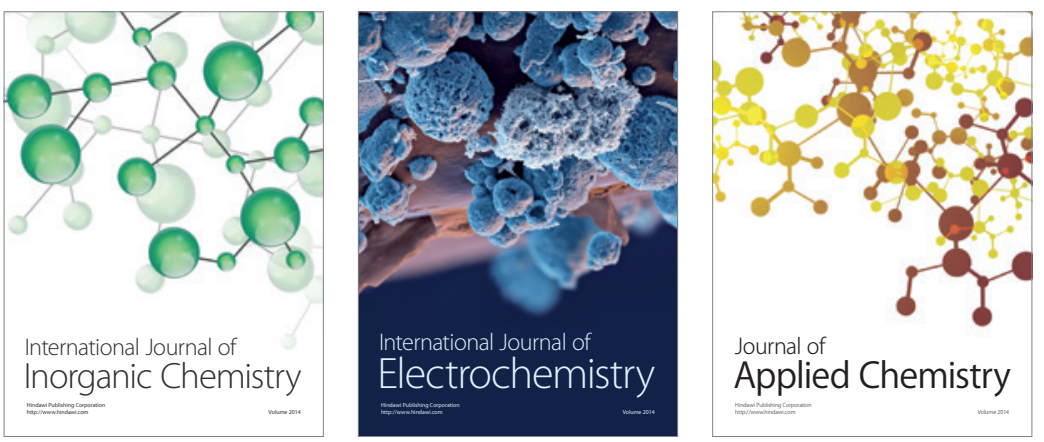

Journal of

Applied Chemistry
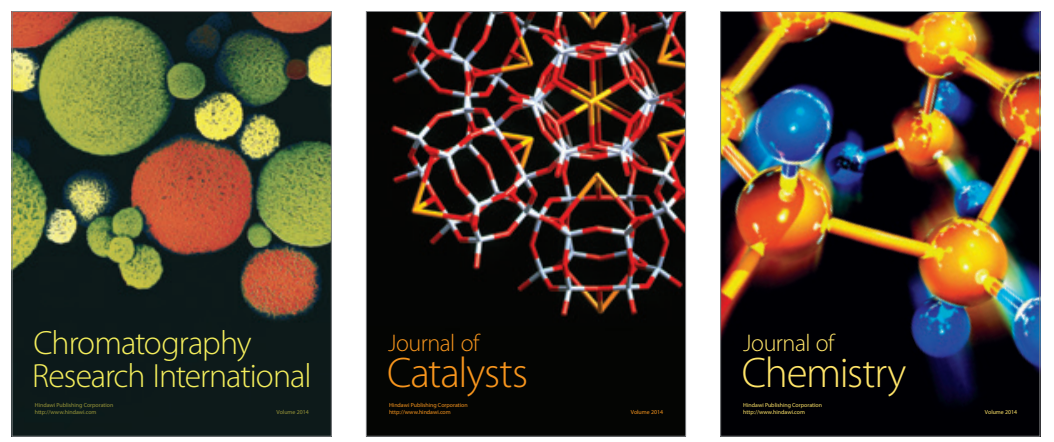
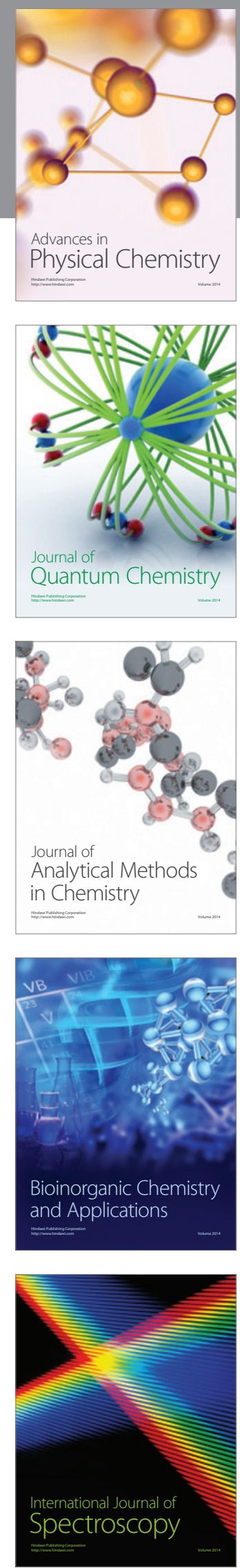